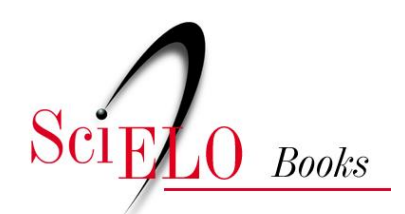

\title{
Civilización y desarrollo amazónico en el discurso y acción del misionero salesiano Carlos Crespi Croci (1891-1982)
}

\author{
Luis Álvarez Rodas \\ José Enrique Juncosa Blasco
}

\section{SciELO Books / SciELO Livros / SciELO Libros}

ÁLVAREZ RODAS, L., and JUNCOSA BLASCO, J.E. Civilización y desarrollo amazónico en el discurso y acción del misionero salesiano Carlos Crespi Croci (1891-1982). In: JUNCOSA BLASCO, J., and GARZÓN VERA, B., eds. Misiones, pueblos indigenas y la conformación de la Región Amazónica: actores, tensiones y debates actuales [online]. Quito: Editorial Abya-Yala, 2019, pp. 137164. ISBN: 978-9978-10-494-1. https://doi.org/10.7476/9789978104941.0009.

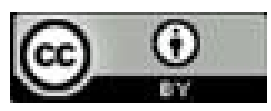

All the contents of this work, except where otherwise noted, is licensed under a Creative Commons Attribution 4.0 $\underline{\text { International license. }}$

Todo o conteúdo deste trabalho, exceto quando houver ressalva, é publicado sob a licença Creative Commons Atribição 4.0.

Todo el contenido de esta obra, excepto donde se indique lo contrario, está bajo licencia de la licencia $\underline{\text { Creative }}$ Commons Reconocimento 4.0. 


\title{
Civilización y desarrollo amazónico en el discurso y acción del misionero salesiano Carlos Crespi Croci (1891-1982)
}

\author{
Luis Álvarez Rodas ${ }^{1}$ \\ lalvarez@ups.edu.ec \\ José Enrique Juncosa Blasco ${ }^{2}$ \\ jjuncosa@ups.edu.ec
}

\section{Introducción y planteamiento del problema}

El presente artículo grafica las articulaciones entre el proyecto de desarrollo de y desde la misión salesiana en la Amazonía — tal como lo imaginó el misionero Carlos Crespi Croci entre los años 1923 a 1936 - con respecto al proyecto de la sociedad azuaya sobre el espacio amazónico circundante, de-

1 Doctor en Estética, Valores y Cultura por la Universidad de Murcia. Docente principal de la Universidad Politécnica Salesiana. Miembro del Grupo de Investigación Misiones y Pueblos Indígenas. Secretario de la Causa de Beatificación del Padre Carlos Crespi Croci sdb.

2 Antropólogo, Doctor en Estudios Culturales Latinoamericanos. Docente e investigador de la Universidad Politécnica Salesiana. Director del Grupo Misiones y Pueblos Indígenas y miembro del Grupo de Investigación Universidad y Bienes Comunes de la misma universidad. 
nominado entonces Oriente Azuayo. Comparecen de ambos sus respectivas visiones del desarrollo, de la colonización de la Amazonía y la civilización del pueblo Shuar. Al mismo tiempo, damos cuenta de las vacilaciones al interno mismo de la misión salesiana que Crespi contribuyó a solventar a medida que desplegó su capacidad discursiva y de acción.

A la vez, esta contribución tiene presente la afirmación de Juan Bottasso (comunicación personal, abril del 2018), según la cual los conflictos y las discusiones entre los misioneros en torno al sentido de su presencia en la Amazonía y entre los Shuar fueron permanentes debido, en gran parte, al perfil de algunos misioneros y al sentimiento de perplejidad ante los constreñimientos surgidos del campo de trabajo amazónico. El misionero Carlos Crespi es una buena muestra de la capacidad de propuesta reflexiva en torno a los interrogantes aún no despejados en su momento.

La figura del misionero salesiano Carlos Crespi Croci (1891-1982) resultó decisiva para la misión a lo largo de los años que permaneció en ella (1923-1936) debido no solo a la fuerza argumentativa de su propuesta sino también por tratarse de un personaje que orbitó siempre entre salesianos de alta jerarquía, sean éstos sus superiores de Roma como el entonces Vicario apostólico, Monseñor Domingo Comín, de quien fue el segundo al mando a lo largo de trece años de tensas relaciones. Su continua referencia a personas de alto rango lo dotó de un aura de autoridad natural, de un margen de actuación tan amplio y de un ritmo tan veloz de toma de decisiones fuera del alcance de sus pares e, incluso, de las autoridades de las que dependía. ${ }^{3}$ Debido a la urgencia de obtener recursos para sostener la misión y cultivar relaciones con las autoridades nacionales y locales, desarrolló gran parte de su actividad fuera del territorio amazónico en un momento crucial caracterizado por la falta de definición del proyecto misionero de desarrollo mando sobre él que "pedí un brazo y me mandan una cabeza". 
y civilización todavía en ciernes, tarea pendiente que asumió de forma inmediata.

Nuestro escrito revela una faceta poco conocida de Carlos Crespi mucho más reconocido por su rol de educador carismáticamente identificado con la clase popular cuencana. Basados principalmente en sus cartas, discursos y escritos, hacemos patente que Crespi trazó el primer intento de una peculiar conceptualización del proyecto de desarrollo de las misiones a partir del cual sumarse al desarrollo regional amazónico. Es decir, el proyecto de desarrollo misionero, entendido en su doble acepción de desarrollo de las misiones y desarrollo de la región desde la misión, es condición y requisito indispensable para contribuir al proyecto de desarrollo regional propuesto por las élites azuayas de tal modo que la relación inversa no es posible.

El itinerario del artículo inicia con una aproximación al personaje remarcando aquellos hitos biográficos y características que lo distinguieron entre los misioneros de su tiempo tales como la formación profesional universitaria (ningún misionero hasta entonces contaba con tal nivel de formación profesional) y su rol de gestor de eventos masivos de propaganda de las misiones que le dieron la oportunidad de reflexionar y madurar desde la tarea de difusión y en el marco de relaciones y vínculos más amplios las dimensiones de su proyecto misionero tan peculiar. En un segundo momento, el artículo se concentra en la identificación de los rasgos del proyecto de desarrollo de y desde la misión, al que Crespi identifica con la categoría de único sistema de civilización y la manera en que se articula diferenciadamente del proyecto de desarrollo regional concebido por las élites azuayas.

La sección identifica los diversos usos e impostaciones del término civilización ya sea puertas adentro, en el marco de las discusiones con autoridades salesianas; sea puertas afuera, cuando Crespi usa el término en discursos público y escenarios de carácter propagandístico. Se concluye con su contribución al proyecto de desarrollo del Oriente Azuayo emprendido por diversas fuerzas sociales de Cuenca. 
Carlos Crespi Croci nació el 29 de mayo de 1891 en Legnano (Milán) y fue el tercero de trece hijos del matrimonio Daniele y Luigia Crespi Croci. Vivió durante 59 años en Ecuador desde su arribo en 1923 hasta su muerte, en 1980. Su presencia en el país tuvo dos fases muy definidas, cada una con sus respectivos y diferenciados aportes: en la primera (1923-1935), ejerció de organizador, difusor e impulsor de las misiones salesianas de la Amazonía desde una posición de colaborador cercano de Mons. Domingo Comín. En la segunda fase (1935-1980), luego de distanciarse de las Misiones por diferencias de estilo y gestión con Mons. Domingo Comín, impulsaría las obras educativas de la ciudad de Cuenca en dependencia directa de las autoridades de la Inspectoría salesiana de Ecuador. Sin duda, se lo recuerda en mayor medida gracias a su aporte en favor de la educación de la niñez y juventud de la ciudad de Cuenca que por su manera de concebir las misiones e imaginar el desarrollo regional del Oriente Azuayo, como era conocida entonces la región amazónica colindante a la provincia del Azuay. Por lo tanto, este artículo ahonda una faceta no tan accesible y conocida del P. Crespi.

Se incorporó a los 12 años al Colegio Salesiano de San Ambrosio y a los 15 años inició la vida religiosa salesiana en Foglizzo (Turín). Culminó la secundaria y, seguidamente, cursó tres años de Filosofía en Valsálice (Turín). Frecuentó la Facultad de Ciencias Botánicas de la Universidad de Padua, y más tarde, el Conservatorio de Música. Realizó cuatro años de intensa búsqueda y clasificación de las plantas de la provincia de Padua e incursionó también en el campo zoológico. En efecto, con un potente microscopio descubrió en las paludes de Comacchio, Venecia, la presencia de "rotíferos de la región antártica" microorganismos traídos por aves migratorias, descubrimiento que despertó interés en los científicos. El 15 de julio de 1921 recibió el Doctorado en Ciencias Naturales en la Universidad de Padua y luego el Diploma de Música en el Conservatorio de la misma ciudad. Por estos antecedentes es, con Miguel Allio- 
ni (+1912), el misionero académicamente mejor preparado de aquellos que pisaron suelo amazónico hasta los años $1930 .{ }^{4}$

Su interés por las misiones de Ecuador se manifestó pronto y de manera muy clara, al punto que las autoridades salesianas le delegaron la organización de la propaganda de las "Misiones Salesianas" mediante el montaje de dos exposiciones misioneras: la de 1925, en el Vaticano, con ocasión del Año Santo; y la de Turín, en 1927, con ocasión de las bodas de oro de las misiones salesianas en América. Para preparar debidamente estos grandes acontecimientos, los superiores le enviaron al Ecuador para que recabe el material para ambas exposiciones e impulse a las misiones. Para entonces, las misiones salesianas ya estaban presentes en la Patagonia Argentina, el Chaco Paraguayo, el Orinoco de Venezuela y en la Amazonía de Brasil y Ecuador todas ellas entre pueblos de "tierras bajas"; por lo tanto, los salesianos se vieron abocados, de improviso, a ejercer su labor con pueblos indígenas dotados de una enorme diversidad lingüística y cultural pero también sumidos en situaciones de sobrevivencia al límite, como los indígenas de la Patagonia argentina y chilena.

Portando la recomendación del Rector de la Universidad de Padua, el P. Carlos Crespi se reuniría en Turín con el Rector Mayor, Don Rinaldi; con el encargado de las misiones, Don Ricaldone (posteriormente Rector Mayor de los salesianos), y con Mons. Domingo Comín, Vicario apostólico de Méndez y Gualaquiza (Ecuador) de quienes recibió el encargo de recaudar materiales para la Gran Exposición Misionera de Roma (1926) y la Exposición Misionera Salesiana de Turín (1927).

El 24 de marzo de 1923 el P. Crespi se embarcaba rumbo a Ecuador con 45 jóvenes salesianos y el 24 de abril anclaba en Guayaquil. Seguidamente viajó a Quito para pedir al Gobierno el permiso de entrada y de exoneración de los derechos de amarilla en 1912. Según Bottasso, poco se sabe de este salesiano que murió tan joven como a los 32 años. Tenía, como Crespi, estudios en ciencias naturales y botánica (Bottasso, 2014, p. 33). 
aduana de la carga transportada. Así comenzó una nueva vida como científico y misionero. Los tiempos se alargaron porque subsistía el veto de entrada de eclesiásticos y a religiosos extranjeros. Aprovechó la espera que se prolongó hasta agosto del mismo año para crear en Quito un ambiente favorable para las misiones salesianas. Ofreció conciertos de piano a todas las Embajadas, en teatros y en las principales familias de la Capital. De Quito pasó a Cuenca donde los salesianos se habían establecido el 14 de marzo de 1893, fijando allí su centro de operaciones a favor de la Amazonía.

Para iniciar las tareas de recolección de muestras de cultura material shuar, flora y fauna y fotografías de las misiones, ingresa a la región Amazónica hacia Gualaquiza, el 23 de noviembre de 1923. La Misión contaba entonces con capilla, residencia misionera, un pequeño internado para niños Shuar, una escuelita para hijos de colonos y pequeños talleres de carpintería y mecánica. Luego de recolectar muestras también en otras regiones del Vicariato, el P. Crespi partió a Génova el 22 de marzo de 1926 desde el puerto de Guayaquil en el buque Venezuela, portando 35 cajones de material para ambos proyectos de exposición, la Exposición Misionera Vaticana de Roma y la Exposición Misionera Salesiana de Turín, no sin antes haber organizado la primera de toda la serie en Guayaquil, en 1924, denominada Exposición Orientalista, una suerte de muestra previa en la que Crespi desplegó gran parte de los materiales y realizó una amplia tarea de promoción y propaganda.

En la Exposición realizada en el Vaticano, se asignaron tres grandes pabellones para las Misiones Salesianas para cuya descripción y análisis del diseño y representaciones de los misioneros en relación a los objetos indígenas se puede consultar el artículo de Pagnota (2018). A la entrada del primer pabellón se podía apreciar la cabaña con todo el ajuar: la cama hecha de caña de bambú, el asiento, el tunduli (tambor ceremonial construido en un tronco de árbol hueco con un orifico encima, según se golpeaba emitía sonidos de fiesta, de duelo, de guerra), la lanza, la bodoquera; cotonas de plumas; una hilera de ollas 
de barro, etc. En la parte externa había algunas jaulas con aves

vivas, un tigrillo y muchas fotos de shuaras y de paisajes de la floresta de la Amazonía ecuatoriana.

En el segundo pabellón, se exponía muestras de herbolaria, una colección de un centenar de musgos, líquenes y especies de helechos de las cuales unas diez eran completamente nuevas y merecieron el nombre de "Crespianas" en su clasificación científica. En el tercer pabellón estaban las fotografías de los distintos centros de misión, escenas de la vida misionera, escuelas, alumnos, estadísticas, etc. La película "Los invencibles shuaras del Alto Amazonas", la primera filmada en Ecuador, se proyectaba en el salón de actos. Centenares de visitantes desfilaban cada día, admirando la magna labor de las misiones católicas en el mundo.

Crespi y la articulación de dos proyectos civilizatorios diferenciados: el proyecto misionero y el proyecto de desarrollo regional

Los aportes y acciones del P. Crespi para incorporar el Oriente Azuayo al desarrollo regional no se entienden sino a partir de su manera de concebir la articulación de ese proyecto con el proyecto misionero. Según nuestra percepción, para Crespi el proyecto misionero no solo tenía prioridad respecto a las exigencias del proyecto regional y en la medida en que este último garantizaba lo primero, lo animaba y apoyaba. Además, como se demostrará en este apartado, si bien usa el término civilización de manera aparentemente unívoca cuando se refiere a ambos proyectos, Crespi no equipara de manera ingenua las dinámicas de la civilización evangelizadora con las dinámicas de la civilización basada en las avanzadas colonizadoras y la explotación de recursos amazónicos. Para ambos casos el rol del misionero es distinto y complementario a la vez y no exento de una cierta crítica y desdén respecto a las consecuencias deshumanizantes de la civilización colonizadora.

A continuación, describimos analíticamente los rasgos de las concepciones diferenciadas sobre el desarrollo en cada uno de los dos ámbitos civilizatorios así como sus interacciones, 
aproximación que arrojará una visión más compleja y no tan accesible de la praxis del P. Carlos Crespi.

\section{El desarrollo del y desde el proyecto misionero}

Crespi arribó a Ecuador en un momento en que la presencia salesiana en las misiones amazónicas aún no se consolidaba al no identificarse estrategias y líneas de acción que garanticen su expansión organizada en el territorio. En 1924, Crespi recorrió Gualaquiza, la primera misión fundada en 1894; y pudo constatar los primeros avances de los salesianos hacia territorios shuar más densamente poblados ubicados hacia el norte es decir, hacia Méndez y Macas, regiones que fueron identificadas desde los inicios de la presencia salesiana como el punto central de la tarea misionera en razón de su densidad poblacional. Para esos años, en Indanza y Cuchiankas, en efecto, se habían iniciado desde 1913 y 1916 internados con cierta dedicación especial a la niñez shuar; y en Macas, iniciaba una escuela, pero en realidad las misiones replicaban en gran parte y con altos y bajos la experiencia de Gualaquiza en la que la escolaridad era ocasional y secundaria frente a otras formas de acción misionera tales como el oratorio, el catecismo y algún tipo de formación en artes y oficio, sin distinguir entre beneficiarios shuar y colonos (Juank 2016, pp. 152-153).

La percepción del momento consistía en que la civilización de los Shuar sería posible si se asumía la figura del colono en tanto modelo para asimilar la educación, la religiosidad y los sistemas de producción, aunque no sin reticencias y dudas, expresadas sobre todo por el mismo Monseñor Comín y basadas en su desconfianza respecto al comportamiento de los colonos (Juank, 2016). A esa práctica incipiente que aglutina y da coherencia a ciertas intervenciones en el territorio la denominamos principio de co-civilización (Juncosa, 2017, p. 130 ss.). La co-civilización que asume la figura del colono de la Sierra como referencia se dejará de lado más adelante, cuando la misión opta por los internados destinados exclusivamente a los Shuar como 
estrategia civilizatoria capaz de integrar la educación y la evan-

gelización a través de la escolarización de la niñez shuar debido al pesimismo y la desconfianza de los misioneros respecto a los Shuar adultos (Juncosa, 2017, p. 132).

A partir de allí, las misiones experimentarán un grado de expansión y crecimiento notables pero ello no ocurrirá sino a partir de los años 1935 en adelante, justo cuando Crespi se retira del Vicariato para enfocarse en diversas iniciativas relacionadas con la educación en la ciudad de Cuenca. En una carta escrita en Quito del 28 de junio de 1923, dirigida al P. Felipe Rinaldi, autoridad máxima de los salesianos, Crespi traza un diagnóstico de la misión que expresa muy bien la sensación de dispersión y desorganización de la acción vicarial. Escrita sin que su autor haya puesto un pie en la Amazonía, la carta debió haber sido inspirada en información que le fue proporcionada por otros misioneros. En ella, los indicadores del diagnóstico pesimista de Crespi sobre la situación misionera se condensan en el término "esterilidad" causada por los siguientes factores:

1. La falta de un plan orgánico de un único sistema de civilización debido al continuo cambio de superiores de las Misiones.

2. Al no estar establecido aún el arte de la escritura de la lengua. La lengua escrita lleva la civilización que permite transmitir los pensamientos propios, e imponer las propias ideas religiosas o civiles... No se ha establecido... una verdadera escuela del alfabeto con escritura de la lengua Shuar... Costará sacrificio, serán necesarios mayores regalos, mayores medios; pero solo haciendo así se podrá aprender la lengua y hacerse aptos para la conversión.

3. No haber establecido buenas haciendas con el cultivo de los mejores productos tropicales, haciendas... que puedan suministrar medios materiales suficientes para el desarrollo de las misiones.

4. No haber tenido los medios suficientes y alguna vez ni siquiera la idea para atraer a la Religión a los indígenas con las maravillas del culto externo...

5. Al no haber pensado nunca en la verdadera constitución de la familia, como entre los bororos. Cuando hayamos 
despejado la inmensa foresta ecuatoriana, tengamos un buen cultivo del ganado, tendremos los medios suficientes, entonces sí podremos promover los matrimonios cristianos, como entre los bororos, regalando el terreno suficiente, la casa, los medios de trabajo, etc.

6. El haber pensado en estos ocho años casi exclusivamente en la cuestión de los caminos... ¿qué cosa se ha hecho verdaderamente orgánico en 25 años? ¿Cuáles shuar han aprendido verdaderamente bien alguna cosa de cristiano, de religioso? (Carta del 28 -06-1923 a Don Rinaldi, desde Quito, pp.3-5, en Henriques 2016, pp. 10-12)

La carta resulta del todo significativa y es un documento clave para el objetivo de nuestro artículo pues evidencia el giro hacia un uso programático del término civilización que pasa de ser una referencia genérica casi siempre al servicio de la promoción puertas afueras de la misión a otra de carácter específico, puertas adentro, dotada de connotaciones e implicaciones organizacionales precisas y, sobre todo, de una fuerza de demanda tal capaz de cuestionar el presente y proyectar la política misionera hacia el futuro. Creemos que es la primera vez que el término civilización se usa en este sentido complejo y en función de articular las líneas maestras del proyecto misionero nombrado como "único sistema de civilización" para referirse a una pluralidad de acciones "orgánicas", es decir, metódicas, planificadas, sistemáticas y constantes en el tiempo tal como expresa en una carta de 1925 a Don Ricaldone:

Lo importante es que se trabaje con método y con un programa bien establecido. Las inspiraciones diarias del Señor me hacen sentir cada día más de modo palpable el futuro de nuestra obra en estas tierras. Pero es importante que se encuentre un núcleo que sintonice con la orden de los superiores mayores y que sea su fiel intérprete, entonces también los muertos resucitarán. (Carta del 22-10-1925 a Don Ricaldone, desde Guayaquil, p. 2, en Enrique 2017, p. 21)

El “único sistema de civilización” da forma a la acción misionera constituida por tres dimensiones jerárquicamente su- 
bordinadas respecto al fin último: la Evangelización, respecto a la cual la civilización asume un carácter instrumental: "nuestro programa de evangelización por medio de aquello secundario de civilización" (Carta del 22-10-1925 a Don Ricaldone, desde Guayaquil, p. 1. en Henriques 1917, p. 21). Cada una de las dimensiones se desdobla en objetivos diferenciados, unos en orden a la sostenibilidad material y simbólica de la misión; otros, en orden a los beneficiarios shuar.

La primera dimensión es la lingüística, tendiente a lograr "el arte de la escritura de la lengua", un canal de doble vía para que los Shuar expresen sus propias ideas a la vez que la misión pueda imponer las suyas en lo que respecto a la religión y la civilidad. La segunda dimensión es la productiva cuyo objetivo es crear haciendas que permitan la sostenibilidad de la misión y, al mismo tiempo, convertirse en escuelas productivas cuyos aprendizajes serán replicados por futuras familias shuar cristianas. La tercera dimensión es la performance litúrgica vistosa y llamativa capaz de atraer la atención y la presencia de los Shuar, un aspecto que evidencia la capacidad comunicativa y la eficacia escénica de Crespi que, sin duda, recoge un rasgo típico de la pedagogía salesiana.

Al mismo tiempo, el último párrafo de la carta denota su molestia ante la presión por construir caminos seguramente, proyecto considerado por Crespi, en un inicio, como urgencia no inserta en una visión estratégica de conjunto. La construcción de caminos es un tema sensible no solo para las élites azuayas sino también para algunos misioneros que trasladaban sin mediaciones las presiones de la sociedad local a la comunidad salesiana lo cual pudo molestar a Crespi.

Pasemos ahora a describir las connotaciones del proyecto misionero de Crespi puertas afuera, donde el uso del término civilización se da en contextos de promoción y difusión de la tarea misionera. Como hemos anticipado, Crespi llegó al Ecuador principalmente para organizar las exposiciones misioneras del Vaticano (1925) la exposición misionera salesiana (1926), en Turín. De esta última se conserva su discurso de clausu- 
ra realizado el seis de octubre de 1926 en el Salón-Teatro del Oratorio Salesiano y cuyo texto consta en el Bolletino Mensille Salesiano de 1926. El discurso es importante porque hace patente la centralidad y especificidad de los objetivos de la misión salesiana frente a los de otras instancias civilizatorias. Al mismo tiempo, añade matices a la caracterización del proyecto misionero de civilización en un contexto nuevo y se refiere a él como civilización cristiana, dotado de una temporalidad y contenidos valóricos distintos respecto al proceso civilizatorio impulsado por el progreso, aunque, de todas maneras, caminen juntos. La civilización cristiana es de rango superior porque es la que, finalmente, humaniza y redime espiritual y socialmente la civilización impulsada por el progreso que arrastra consigo consecuencias indeseables. En el siguiente párrafo del discurso de clausura aparece esta distinción:

Observad los mapas, los croquis e itinerarios de los viajes emprendidos por estos adalides de la civilización que se llaman los misioneros salesianos y os referirán toda una epopeya de sacrificios, de martirios, de renuncias, de dolores, de luchas, de derrotas y de gloriosas victorias. Una pequeña línea sobre el mapa condensa toda una vida de humildad y de sacrificio. Un pequeño punto, señala un foco poderoso de admirables obras de caridad, humanitarias y apostólicas. Quizás al lado de estas mismas líneas y de estos mismos puntos, otros señalarán expediciones y centros de comercio, yacimientos de petróleo, haciendas colosales con millares de cabezas de ganado, emporios de materias primas, descubiertos y organizados por otros hombres; pero ¡qué diverso es el espíritu que los anima, la fuerza que los impulsa, el tesón que los sostiene en aquellas zonas inhóspitas!

Ya que, mientras el interés, el afán de gloria, de riquezas, de dinero, pueden hacer que algunos sigan las huellas del misionero, bien distinta es la fuerza grande y sublime que anima al humilde héroe de Cristo, el amor: amor a los débiles, a los humildes, a los oprimidas, a los enfermos; el deseo puro, ardiente, desinteresado de elevarlos a las altas esferas de la verdadera, de la única civilización, la civilización cristiana. (Bolletino Mensile Salesiano, octubre de 1926, traducción de Luis Álvarez) 
Concretar y sostener la civilización cristiana en las tierras

de misión implica un saber hacer, echar mano de métodos y tácticas pautadas y repetitivas eslabonadas entre sí, a la manera de una secuencia con dos objetivos muy claros e innegociables: generar sostenibilidad simbólica y sostenibilidad financiera. El primer paso del proceso inicia con performances públicas de propaganda, como las exposiciones misioneras mencionadas, uno de cuyos objetivos es construir la centralidad de la figura del misionero, destacando su liderazgo heroico al frente de una epopeya de grandes dimensiones aún a costa de silenciar la situación de los pueblos indígenas o exponerla desde una mirada exótica. Decía Crespi en su discurso de clausura de la Exposición misionera de Turín:

$\mathrm{Al}$ ver las serpientes venenosas, embalsamadas o conservadas en alcohol, pensemos que las más de las veces estos reptiles son documentos de lúgubres escenas, acaecidas en parajes solitarios y de las cuales fueron víctima muchas veces, los misioneros, las monjas, o los queridos salvajes.

Y cada collar, cada lanza, cada pájaro, cada objeto, nos recuer$\mathrm{da}$, en su mudo lenguaje, la epopeya heroica de sacrificios de centenares y millares de salvajes, nos canta el amor de centenares de misioneros y de hijas de María Auxiliadora, que se inmolan en un duro trabajo de elevación, de sacrificio, de dolor. Señores, la Exposición Misionera Salesiana ha terminado; pero para los Misioneros salesianos empieza una era de actividad y de conquistas cuya magnitud solo la Divina Providencia conoce. El Venerable Don Bosco en sus sueños admirables tuvo la intuición del colosal desarrollo de la obra misionera de sus hijos en todas las latitudes del globo y casi parece que la divina Providencia, como Madre amorosa, tiene especial empeño en convertirlos en realidad, para la salvación de millones y millones de almas. Centenares de nuevas fundaciones en las inmensas cuencas del amazonas, del Orinoco y del Plata; una red inmensa de institutos de educación en la India, China, Japón y Australia; nuevas misiones en el Continente Africano, doquiera presenciaremos un florecer de admirables obras de amor, de fe, de sacrificio, para la redención y elevación de centenares de pueblos que yacen en las oscuras tinieblas del error; doquiera 
el místico árbol de la Congregación Salesiana extenderá sus ramas, ricas de nuevos retoños y a su benéfica sombra se acogerán las nuevas generaciones cristianas. Nosotros, los misioneros, todos los días rogaremos a Dios que aumente siempre más en nuestros corazones el verdadero espíritu apostólico a fin de que se agigante en ellos aquella verdadera fe de los santos que convierte y vence; que nos infunda como una segunda naturaleza, el espíritu de sacrificio que se inmola hasta el martirio, hasta la muerte. $\mathrm{Y}$ vosotros, señores, acompañadnos en este esfuerzo supremo con la oración, con la propaganda, con el sacrificio y con vuestro óbolo, seguros de que cooperando a divulgar hasta los últimos confines de la tierra la religión de Cristo y el amor y devoción a su Santísima Madre y a su fiel siervo Don Bosco, llevaréis a cabo una meritísima obra de fe y de redención religiosa y social ... (Bolletino Mensile Salesiano, octubre de 1926, traducción de Luis Álvarez)

La recolección de fondos a través de conferencias científicas o misioneras que denotaban una gran capacidad de manejo de grandes audiencias y de montaje de exhibiciones y jornadas festivas, experticia muy marcada en Crespi quien llegó a organizar colectas en Italia incluso un año antes de llegar a Ecuador, en 1922. En la misma carta — relación sobre el uso de fondos entre 1922 y 1935 Crespi relata lo siguiente:

Con los debidos permisos, compradas máquina y diapositivas misioneras de la Patagonia y del Mato Grosso, se comenzaron conferencias y fiestas misioneras en la diócesis de Milán y de Lodi, y con el apoyo del Honorable Vassallo, subsecretario del Ministerio del Exterior, se pudo interesar a su Excelencia Benito Mussolini que diera muchos materiales logísticos, sanitarios, científicos por el valor de cerca de cincuenta mil liras. ("Breve Relación de los Fondos recogidos por el P. Carlos Crespi desde noviembre de 1922 a noviembre de 1935”, del 31-12-1935, p. 4)

Henriques detalla, a partir de los datos de la misma carta, que la campaña de propaganda en Italia:

Reportó cerca de 15000 liras gastadas en los viajes de transporte de materiales y de máquinas. Asimismo, diferentes in- 
dustriales milaneses ofrecieron algunos quintales de tejidos equivalentes a cerca de 80000 liras, que fueron repartidos posteriormente a los pueblos autóctonos. (Henriques, 2017, p. 32)

La información revela también que, para entonces, el regalo de telas a los Shuar ya era una práctica consolidada para atraerlos a la misión según dinámicas de intercambio mediante las cuales los Shuar asistían a la catequesis a cambio de telas y prendas de vestir

En Ecuador, Crespi diseñó distintos tipos de eventos masivos para producir adhesiones o reclutamiento tales como la activación de grupos locales de apoyo, constituidos con miembros prominentes de las grandes ciudades y autoridades convencidas de la legitimidad del proyecto y dispuestas a contribuir desde las decisiones y políticas públicas. De esa manera Crespi activa por primera vez —creemos - un Comité Patriótico Orientalista de Señoras, fruto de la Exposición Orientalista realizada en Guayaquil en la Plaza de la Catedral de Guayaquil y la casa del literato Víctor Manuel Rendón con los materiales recolectados para la exposición en el Vaticano (Henriques, 2017, pp. 35-36). En una carta-relación de los fondos administrados entre 1922 y 1935, Crespi evalúa de la siguiente manera el alcance propagandístico de la muestra:

La Exposición duró cuarenta días y se tuvieron cerca de 120 conferencias a todos los alumnos de las escuelas públicas y privadas, inferiores y superiores. Los visitantes fueron treinta mil. ("Breve Relación de los Fondos recogidos por el Padre Carlos Crespi desde noviembre de 1922 a noviembre de 1935”, del 31-12-1935, p. 6 en Henriques, 2017, p. 34)

En efecto, Henriques asevera a partir de los datos reportados en la misma carta que, una vez culminada la tarea de recolección de materiales:

... el P. Carlos envió los materiales a Turín, y comenzó la propaganda por los periódicos, llegando a fundar un Comité Orientalista de Señoras. Toda esta actividad aportó 12053 sucres, que equivalían en ese tiempo a 50000 liras. También las casas comer- 
ciales se interesaron para que la Standard Oil ofrezca cables de acero por el equivalente a doscientos mil sucres. Por otra parte, otra campaña efectuada en la capital a fines de diciembre con el Gobierno Ecuatoriano permitió conseguir 10460 sucres para la carretera Pan-Méndez. (Henriques, 2017, p. 34)

Crespi activó su perfil de científico también al servicio de la propaganda. En efecto, desde octubre de 1928 hasta agosto de 1929 se radicó en Estados Unidos para llevar a cabo un impresionante raid que incluyó su participación en un congreso científico y la organización conferencias en 32 diócesis (Henriques, 1917, p. 37). Los fondos recolectados fueron destinados, en parte, a financiar la que sería la primera película rodada en Ecuador. Los hechos anotados hablan muy bien del talento de comunicador y propagandista con el propósito muy claro y preciso de obtener recursos financieros que garanticen la sostenibilidad del proyecto misionero.

La capacidad de negociación directa y de cabildeo ante las autoridades del Estado fue un renglón al que Crespi le destinó energías considerables desde los inicios de su estadía en Ecuador. Esta experticia se convertirá en un saber hacer consistente a lo largo del tiempo para las autoridades salesianas no solo del Vicariato sino también del Ecuador. El objetivo fue siempre obtener ayudas estatales y lograr un régimen legal diferenciado y ventajoso. Dice en una carta de 1929 dirigida a Don Ricaldone, tras desactivarse, por su ausencia en Estados Unidos, el régimen especial de aduanas que beneficiaba las importaciones de los salesianos:

Importantísimo: hice poner nuevamente en vigencia la ley hecha aprobar por mí, hace unos tres años que exonera toda mercadería para las misiones: medicinas, vestidos, tejidos, libros, instrumentos mecánicos, de agricultura, en fin, todo lo que sirve para las escuelas agrícolas, colegios, hospitales, orfanatorios. (Carta del 12-10-1929 a Don Ricaldone, desde Quito, p. 3 en Henriques, 2017, p. 33)

Pero más allá de ello, el ejercicio de la negociación directa con autoridades estatales refleja la presencia de un elemento 
más profundo que trasciende salir al paso cubrir necesidades concretas y consiste en la conciencia de especificidad y autonomía de la misión frente a proyectos impulsados por otras fuerzas sociales. Dice al respecto en una carta de 1934 :

Esta presión con los gobiernos es una obra de alta espiritualidad misionera, y fundamental para tener libertad de acción en nuestro campo religioso. Persuadido que sin grandes medios materiales no se puede hacer la guerra al Diablo, jefe absoluto e imperturbable en casi la totalidad del Vicariato, y siendo la actual esfera de acción misionera los límites del reino shuar, y permaneciendo aún aislada las dos terceras partes de su territorio, comencé un peregrinaje de propaganda... (Carta del 11-07-1934 a Don Berrutti, incompleta, pp. 1-2, en Henriques 2017, p. 26-27)

La tarea de negociación y constante acercamiento con el Estado fue tan eficiente que, incluso, provocó que el mismo Estado requiera a los salesianos hacerse cargo de gran parte de la educación laica, lo cual no prosperó y con seguridad, debido a la conciencia de especificidad y autonomía del proyecto misionero salesiano que no dejaba espacio a proyectos ajenos. En la misma carta dirigida a Don Ricaldone dice al respecto:

El Gobierno del Ecuador ofrece a la Misión Salesiana todas las escuelas laicas que sostiene en nuestro Vicariato, y quiere dárnoslas a nosotros para que con plena libertad de programa y según nuestros sistemas atendamos a la educación de la juventud que allí existe. (Lo hace porque ha visto el óptimo éxito de la escuela de Macas que contraté hace unos tres años, y el éxito nulo de las escuelas que él sostiene). (Carta del 31-10-1929 a Don Ricaldone, desde Quito, p. 1 en Henriques, 2017, p. 38)

El último eslabón de su visión expansionista del proyecto misionero y de sostenibilidad en el tiempo es la generación de iniciativas educativas fuera del territorio de misión a las que consideró fuentes programables de recursos humanos permanentes que, a la final, garantizarán la sostenibilidad del proyecto misionero basado en dos propuestas de formación para los Shuar: escuelas agrícolas y escuelas de artes y oficios. Es decir, 
la misión se sostendrá con el personal provisto por las mismas obras educativas salesianas de la ciudad de Cuenca que replicarán en la Amazonía su experiencia de formación:

... es indispensable tener en Cuenca una Escuela Agrícola y una Escuela de Artes y Oficios que sean una base de impulso y de emulación para las obras orientales: teniendo aquí en Cuenca una buena fuerza de personal misionero seguramente podremos organizar mejor las obras internas. Monseñor, haga suya la idea, apóyela ante los superiores. Cuenca es y debe ser misionera, absolutamente misionera, exclusivamente misionera. Para esto yo dispongo de fondos dirigidos para las Misiones, porque de aquí deben salir y regresar los misioneros. De aquí y solamente de aquí deben partir el espíritu y la iniciativa misionera: Cuenca debe ser una vía potentemente organizada para el desarrollo de nuestras escuelas agrícolas y profesionales en el Oriente. (Carta del 10-06-1934 a Monseñor Comin, desde Cuenca, pp. 1-2 en Henriques 2017, p. 50-51)

Crespi comparte y ahonda el mismo estereotipo racializado de la sociedad de su tiempo y de los misioneros salesianos sobre los Shuar, enfatizando con la abundante empiria proporcionada por los escritos y relatos misioneros su carácter violento y arbitrario como síntoma de su niñez y, por lo tanto, sujetos posibles de acciones pedagógicas:

La inscripción de los Shuar como pueblo 'pérfido, astuto, soberbio, egoísta'... es tal vez el lugar común más persistente... [de los misioneros salesianos] apareciendo una y otra vez hasta convertirse en marca étnica asociada con la irracionalidad infantil, sustrato de una actitud arbitraria, sin objeto, impropia de una razón que debe evaluar el presente y arribar a conclusiones definidas... El misionero Carlos Crespi enlaza, además, la niñez del pueblo Shuar con la violencia temperamental: "En medio de tanta soberbia, en medio de un carácter tal libre e independiente, se ve siempre al hombre primitivo, al niño de la civilización". (Crespi [1926] 1993, 419), situándolos así en la jurisdicción de la intervención misionera. (citado en Juncosa 2017, p. 158)

Además, asume el pesimismo de los misioneros respecto a los Shuar adultos con los cuales resulta imposible lograr algo en 
términos de civilización y evangelización. Por ello, la única salida

para civilizar a los Shuar será la escolarización de su niñez, proyecto que se concretaría apenas poco después con los internados. No obstante, Crespi aporta otros planteamientos que señalan distancias importantes con las percepciones del sentido común de la sociedad y muy posiblemente de algunos de los misioneros. Una de las diferencias de percepción consiste en desestimar la posibilidad de asimilación total de los Shuar mediante el mestizaje, convencimiento que surge de la evidencia proporcionada por los misioneros que advirtieron una fuerte resistencia de los Shuar a mezclarse con los colonos. En una entrevista del diario El Comercio (14 y 15 de abril de 1928) Crespi:

Anuncia el abandono del mestizaje como posibilidad civilizatoria debido a la negativa shuar $\mathrm{y}$, respecto a la niñez, dijo lo siguiente:

¿Cree usted en el mejoramiento de la raza?

Esto lo creo muy difícil. El jíbaro tiene una grande aversión al matrimonio con blancas y, a pesar del trabajo de los misioneros, conserva rígidamente sus tradiciones familiares y raciales. Sólo las nuevas generaciones de niños, educados modernamente, podrán tal vez permitir un acercamiento más fácil a nuestra civilización. (Entrevista de El Comercio, 15 -04-1928, en Juncosa, 2016, p. 131)

El segundo elemento que denota una posición propia de los misioneros recogida por Crespi es el lugar asignado a la diferencia cultural shuar en contextos de desarrollo y colonización y su postura asevera el principio mediante el cual la asimilación a la civilización es la única posibilidad de otorgar algún tipo de oportunidad a su continuidad cultural.

Crespi y el proyecto de desarrollo regional del Oriente Azuayo

Crespi se insertó prematuramente en un clima de urgencia que rodeaba el proyecto de colonización amazónica organizada planteado desde la sociedad azuaya para el espacio 
amazónico adyacente denominado Oriente Azuayo. En 1922, se presentó a las autoridades italianas, antes de emprender su viaje a Ecuador, armado con un proyecto de colonización del cual no conocemos los detalles de su contenido pero que muy posiblemente privilegiaba la construcción de una vía de acceso al Oriente Azuayo, seguramente la vía Pan-Méndez, de la que otro misionero, el P. Albino Del Curto sería su promotor. Vale notar que tal proyecto seguramente entregado en sus manos por Monseñor Comín expresa no solamente las expectativas de la misión sino también las del gobierno de Ecuador. Al respecto, Álvarez refiere que:

... el 24 de julio de 1922 hizo formal petición a los superiores para ir de misionero y ellos lo destinaron al Ecuador. A mediados de 1922 va a Roma para pedir ayuda a las autoridades del Gobierno italiano a quienes presenta también un pequeño proyecto de colonización, de acuerdo con el Gobierno del Ecuador. El Gobierno italiano fue pródigo con las misiones: máquinas fotográficas, una máquina de cinematógrafo, una máquina para escribir el idioma Shuar, brújulas, teodolitos. Niveles, pluviómetros, una gran caja de medicinas y aparatos, toda clase de herramientas de labranza, carpas, etc. (Álvarez, 2001, p. 10)

Así, de manera intempestiva, el P. Crespi se vio involucrado en los avances y retrocesos de los intentos de integración regional del Oriente Azuayo en un ambiente cargado de exigencias y reclamos entre diversos actores ante los intentos fallidos y los pendientes por lograr, especialmente relacionados con la concreción de una vía de acceso a la Amazonía.

A partir de su arribo a Ecuador (1923), el P. Crespi se inserta, de a poco, en los avances y retrocesos del proyecto regional del Austro relacionados con la integración del Oriente Azuayo a medida que ocurren en la región sucesivas transformaciones socioeconómicas. Tal como reportan Espinoza y Achig (1979, p. 51 ss.), hacia 1911, la economía del Azuay y Cañar culmina un periodo que pasó de una agricultura de subsistencia a otra de expansión de la agroindustria proveedora de bienes y salarios a otras regiones (especialmente a Guayaquil) y 
de manufactura excedentaria concentrada en la producción del sombrero de paja Toquilla que alcanzó altos precios internacionales (1979, p. 96).

No obstante, en esta etapa, la integración regional de la Amazonía se vio obstaculizada por la incomunicación, el principal factor del fracaso de sucesivos proyectos de colonización. Para 1917 existían dos senderos para acceder al Oriente Azuayo: Sigsig- Gualaquiza y Gualaceo- Indanza (Espinoza \& Achig, 1979 , p. 81) pero ninguno de ellos ofrecía condiciones mínimas para el transporte de bienes y productos. A ello se debe añadir el descentramiento de la región debido a la construcción del Ferrocarril Guayaquil-Quito que generó un eje de comunicación que dejó a Cuenca al margen.

El misionero salesiano Miguel Allioni, en sus apuntes etnográficos sobre los Shuar de Bomboiza, redactados hasta 1910, es testigo privilegiado de las implicaciones amazónicas de esta situación y del carácter marginal de la economía del Austro basada en un sistema de latifundios parcialmente arrendados a colonos según la modalidad productiva denominada "entable", un tipo de asentamiento precario que servía de base para la recolección del caucho y la canela, para la siembra de paja toquilla en Gualaquiza, muy apreciada su resistencia (Espinoza \& Achig 1979 , p. 104), arroz y producción de alcohol de caña, principalmente, combinada con la explotación del oro en las riberas de los ríos. Allioni, también da cuenta de las expectativas del proyecto de colonización extranjera promovido por el holandés Fabre que, finalmente, fracasó. Allioni, seguramente, produjo un legado de expectativas de progreso de la región amazónica e identificó pautas que, como veremos después, serán asumidas casi al pie de la letra por Crespi.

El P. Carlos Crespi experimenta en Cuenca un escenario socioeconómico impulsado por la expansión y auge de la economía exportadora de paja toquilla (1912-1925) pero apenas antes de la crisis del modelo exportador cacaotero (Espinoza \& Achig, 1979, p. 101 ss.) debido a la disminución de la producción y a la devaluación del sucre respecto al dólar. En esta 
etapa, la producción de sombreros de paja toquilla pasa de un modelo de producción manufacturera familiar a otro condicionado por el modelo comercial en torno a la demanda de Estados Unidos y cuyo eslabón final son los exportadores. Cuenca es el epicentro de una ola modernizadora comercial y de servicios impulsada por la exportación del sombrero de paja toquilla, pero nuevamente, la vialidad y las comunicaciones persisten como problemas sin resolver, tal como lo registra Octavio Díaz:

El camino del sur termina en la parroquia de Cumbe; en dirección para El Oro la vía avanza hasta Portete, el camino a Naranjal que costó muchos esfuerzos y gastos se encuentra en total abandono, el camino al norte termina en El Descanso, además no existe entrada al Oriente. (Díaz, 1919, p. 19, citado en Espinoza \& Achig, 1979, pp. 112-113)

Crespi se suma al proyecto de la sociedad azuaya, pero percibimos, a la luz de las cargas analizadas que estaba más preocupado en desarrollar su propio proyecto que en involucrarse de lleno en el proyecto regional. En realidad, Crespi forjó su propia idea de desarrollo a partir de la misión sin por ello dejar de alentar y solidarizarse con los intentos locales. En este contexto, vuelca su noción de desarrollo regional en un capítulo que le confió el editor y autor de la Monografía del Azuay, publicado en 1926. Las líneas de su capítulo se basan en gran parte, nos atrevemos a conjeturar, en la propuesta del misionero salesiano Miguel Allioni, fallecido en 1912, que consta en el primer informe etnográfico sistemático que se conozca de un misionero salesiano posiblemente elaborado entre 1910 y 1911. En ese informe, ${ }^{5}$ Allioni propone líneas de acción para la colonización y el desarrollo regional que Crespi retomará con notables concordancias especialmente en lo que atañe a la colonización extranjera de la Amazonía y al optimismo colonizador que alimenta un lenguaje épico del desarrollo basado en dos pi- 
lares: las colonias agrícolas y la explotación de recursos mineros entones considerados inagotables.

Hacia finales de los años 20, Crespi se involucra muy activamente y de lleno con autoridades locales en proyectos de colonización. En una entrevista en el diario El Comercio (15 y 16 de abril de 1928), relata una expedición con el entonces Ministro del Oriente, el Gobernador del Azuay y personalidades educativas de Cuenca. La entrevista narra las vicisitudes de un viaje de fiscalización de los avances del camino Pan-Méndez, emprendido por el misionero Albino Del Curto en 1915 y que contó con fondos del Estado otorgados a los salesianos en 1925.

Esa entrevista es importante porque permite identificar el tipo de articulación de la misión con los proyectos públicos y de la sociedad local, apenas cinco años después de haber Crespi arribado al Ecuador. De la lectura de la entrevista, surgen algunos elementos importantes de la praxis de desarrollo de Crespi y de la misión salesiana.

Frente a las autoridades locales, la misión estaba dotada de una visión más integral y capacidad de mayor concreción en el territorio para establecer y garantizar la permanencia de la colonia de Méndez, para la cual el camino era vital:

Por otra parte, toda la Misión Salesiana del Ecuador que se compone de 50 misioneros está decidida a no desmayar hasta entregar a la colonia de Méndez un cómodo y seguro camino de penetración. (Diario El Comercio, Entrevista con el Reverendo Carlos Crespi... 15 y 16 de abril de 1928)

El camino Pan-Méndez y las obras civiles conexas (puentes, línea telefónica, etc.) muestra la confluencia de intereses entre la misión y los proyectos públicos al punto que los misioneros aportaron fondos propios recabados desde los inicios, en 1915, incrementados en 1924 por lo recaudado de la Sociedad Patriótica Orientalista de Señoras de Guayaquil, y por el mismo Estado, otorgado por contrato de ejecución de obrar, en 1925:

El Gobierno ya entregó cuarenta y ocho mil sucres y debe todavía sesenta y dos mil, los que va abonando regularmente por 
mensualidades. Además, tenemos una cantidad suficiente para acabar el gran puente sobre el río Namangosa, cantidad colectada por las cultas damas del Comité Patriótico Orientalista de Señoras de Guayaquil. (Diario El Comercio, Entrevista con el Reverendo Carlos Crespi... 15 y 16 de abril de 1928)

Y, por último, destacamos el perfil del proyecto de desarrollo materializado en la "colonia" Méndez cuya vitalidad y vigencia aparece en la entrevista como resultado de la acción misionera; es el misionero entrevistado el que otorga credibilidad a la empresa. Las "colonias" están constituidas por residencias estables de colonos separados de los asentamientos shuar y, ambos, "progresan", cada uno a su ritmo. La crónica periodística destaca actividades de puesta en escena del civismo de colonos y Shuar así como un vívido sentido de defensa de las fronteras ante el Perú, un componente muy sensible de la legitimidad de la misión de alguna manera garante de las fronteras nacionales. $\mathrm{Al}$ respecto, responde Crespi al periodista:

Mucho se ha hablado de la colonia de Méndez, de su progreso, de su importancia, ¿hay algo de exageración en eso? Ya habrá leído en los periódicos del juicio emitido por el señor doctor Córdova Toral, actual Ministro de Instrucción Pública. Le puedo decir solamente que el día 19 de marzo, cuando el pabellón patrio se levantaba en el suelo oriental, la plaza de la Misión representaba un conjunto de fuerzas unidas, verdaderamente conmovedor. Los centenares de colonos presentes con sus niños, con sus mujeres, contentos de su estado, manifestaban claramente que ya existe en Méndez una voluntad decisiva, un pacífico ejército de hombres que parecen repetir con sagrado orgullo; "Esta tierra es nuestra, de aquí no se pasa".

¿Entonces en Méndez, hay una verdadera ciudad? Ni ciudad, ni pueblo verdadero. Hay fuertes reuniones de jíbaros en las alturas que coronan la misión y más de 600 colonos repartidos al lado del camino y del valle de Paute. Los núcleos más importantes de colonos viven en Santa Elena y en Copal, con 40 familias más o menos, y otras 70 familias están alrededor de la Misión Salesiana y de la Tenencia Política. (Diario El Comercio, Entrevista con el Reverendo Carlos Crespi... 15 y 16 de abril de 1928) 
A partir de la documentación analizada es posible aseverar que el P. Carlos Crespi fue un personaje que irrumpió en las misiones amazónicas en un periodo de transición y de expansión de la presencia salesiana más allá de la primera frontera, ubicada en la región de Gualaquiza. Su perfil estuvo dotado de rasgos muy especiales respecto a los salesianos de su tiempo y casi seguramente fue el primero que adelantó para su época una visión integral del proyecto misionero en la Amazonía ecuatoriana que, hasta entonces, se habría paso a fuerza de replicar experiencias conocidas y responder, vez por vez, a las dificultades que se presentaban.

A pesar de participar del paradigma de co-civilización de los Shuar que requería de la presencia modélica del colono, Crespi, se toma el escenario para instaurar la necesidad de imaginar un proyecto de carácter sistémico e integral y propiciar una mirada a muy largo plazo que incluía, por ejemplo, la visión de generar permanentemente recursos humanos que otorguen sostenibilidad en el tiempo a su proyecto de civilización y colonización basado en la agricultura y las artes y oficios.

No obstante, su manera de ver las cosas requería de capacidades muy especiales que se condensaban en él -y tal vez solo en él- de manera muy peculiar, tales como el manejo de la comunicación y organización de eventos propagandísticos, el cultivo de alianzas estratégicas con instancias de la sociedad local y la contundencia para emprender negociaciones vis a vis con autoridades del Estado.

Pero su visión resultó prematura respecto a los constreñimientos de la realidad y también debido a su estilo extrovertido que proyectó su acción desde afuera hacia dentro de la Amazonía, más a favor del Vicariato que dentro de él. De hecho, el contacto con la realidad cotidiana de las misiones fue muy discreto y puntual a lo largo de los años que acompañó a Monseñor Domingo Comín. Su estilo comunicativo frondoso e imaginativo y su amplia visión resultó, asimismo, asincrónico y 
prematuro respecto al ritmo de toma de decisiones de su obispo y de los salesianos con los que tuvo que compartir el trabajo.

Nuestra contribución muestra que Crespi tuvo una clara conciencia de los elementos distintivos del desarrollo regional amazónico concebido desde el proyecto misionero, diverso a la vez que contemporáneo en relación al proyecto de desarrollo regional amazónico impulsado por la sociedad azuaya. Carlos Crespi genera la categoría de único sistema de civilización mediante la cual otorga carácter discreto y sistémico a su propuesta de desarrollo misionero (por ejemplo, es el primer misionero que usa con rigor el término "programa") basado en los valores de la civilización cristiana que humaniza y corrige las consecuencias de la civilización impulsada por el desarrollo económico y productivo.

Si bien es necesario apoyar los impulsos de este último, la prioridad la tenía el proyecto de desarrollo de la misión y desde la misión. La principal implicación de esta relación jerárquica consiste en que Crespi no plegó en su totalidad al proyecto regional propio de las élites del Austro marcando distancias, reparos y diferencias, aunque sutiles, no menos firmes y reales. La conciencia de la diferencia y autonomía del proyecto misionero frente a otros posibles, estimamos, no fue obvia en otros misioneros cuya disponibilidad incondicional con las élites locales pudo generar conflictos al interno de la misión.

Miradas las cosas a la distancia, algunas pautas de su proyecto pervivieron o fueron retomadas posteriormente en tanto que otras fueron dadas de baja por la fuerza de la realidad y los acontecimientos posteriores. Por ejemplo, su visión de instaurar en Cuenca escuelas agrícolas y de artes y oficios para alimentar la mano de obra de la colonización se intentó alrededor de los años 1960 (con el Colegio Orientalista y el Agronómico de Paute) pero no funcionó con la articulación regional que se esperaba. El proyecto de montar poblados shuar alrededor de las misiones con hogares shuar modelados a imagen y semejanza de las familias colonas de la Sierra dedicadas a la agricultura y la ganadería se implementó también por esa misma década, 
por ejemplo, en Bomboiza, pero la idea no prosperó debido a

barreras culturales obvias y, luego, porque que la misión promovió desde la Federación de Centros Shuar otras dinámicas productivas.

Quedó como legado de la praxis de Crespi para la forma de acción colectiva de los misioneros su capacidad para emprender negociaciones directas con el Estado, capacidad que se acentuó en el tiempo; y una sensibilidad muy fina de la especificad del proyecto misionero dotado de una fuerza y lógica irreductible respecto a otras propuestas. Uno de los resultados de esta sensibilidad que empuja a optar por proyectos específicos alimentados desde dentro de la vida misionera será el proyecto que abandone el paradigma de co-civilización para dar lugar a una forma de misión distinta respecto a los Shuar, presencia misionera que se situará al margen y en conflicto con el proyecto de aquellos otros misioneros que optarán, en cambio, por animar y promover la colonización.

\section{Bibliografía}

Aij'Juank (Alfredo Germani sdb). (2016). Pueblo de fuertes. Tomo 3. Quito: Abya-Yala.

Álvarez Rodas, L. (2001). Padre Carlos Crespi Croci el apóstol de los pobres: Cuencano ilustre del siglo XX. Editorial Don Bosco. Allioni, M. ([1909-1910] 2014). El Pueblo Shuar. En: Juan Bottasso (Comp.), Los salesianos y la Amazonía. Tomo II. Relaciones etnográficas y geográficas. Quito: Abya-Yala.

AA.VV. Bolletino mensile delle opere e missione salesiane (1926), Turín: Archivo de la Postulación General de las Causas de la Familia Salesiana, Roma.

Bongioani, M. (1989). Carlo Crespi Missionario e scienziato, En Ivan Tagliaferri y Elio Gentile, Sciencia e fede i protagonista (pp. 277-286). Novara-Italia: Instituto geográfico De Agostini,

Crespi, P. C. (1926). El Oriente Azuayo. En: Luis Fernando Mora y Arquímedes Landázuri, Monografía del Azuay. Cuenca: Tipografía Burbano.

Díaz, O. (1919). Monografía del Cantón Cuenca. Tipografía Municipal: Cuenca. 
Espinoza, L., \& Achig, L. (1979). Proceso de desarrollo de las provincias de Azuay, Cañar y Morona Santiago. Centro de Reconversión Económica del Azuay, Cañar y Morona Santiago (CREA): Cuenca.

Esvertit Cobes, N. (2014). Los Salesianos en el Vicariato Apostólico de Méndez y Gualaquiza. En: José Juncosa et al. (coords.), La presencia salesiana en Ecuador. Perspectivas históricas y sociales (pp. 471-512). Quito: Abya Yala, UPS.

Henriques, A. (2013). Lectura critica de las cartas del P. Carlos Crespi. Quito: Abya-Yala.

Juncosa, J. (2017). Saber para prevalecer. Civilización, educación y evangelización en el territorio shuar: educaciones, epistemologías y métodos en disputas. (Tesis doctoral en Estudios Culturales Latinoamericanos). Quito: Universidad Andina Simón Bolívar.

Mora, L. F., \& Landázuri, A. (1926). Monografía del Azuay. Cuenca: Tipografía Burbano.

Pagnotta, Ch. (2018). La Exposición Misional Vaticana de 1925, los misioneros salesianos y la representación del Oriente ecuatoriano. Procesos, Revista Ecuatoriana de Historia, 47, 59-88 (enero-junio). Quito: Universidad Andina Simón Bolívar.

\section{Fuentes documentales}

- Carta de recomendación del Professore Luigi Lucatello, Rettore magnifico dall'Università di Padova, 16 de noviembre de 1922, Archivo de la Postulación General de las Causas de la Familia Salesiana, Roma.

- Diario El Comercio: Entrevista con el Reverendo Carlos Crespi, misionero salesiano, a su regreso de la Región Oriental de Méndez, a donde partió en compañía del Gobernador de la Provincia del Azuay; 15 y 16 de abril de 1928.

- Textos de 1919, 1920 y 1922, tomados de su diario. Unos han sido transcritos por Daniel López y otros por Luis Álvarez. En Cordero, Juan (2013), Siervo de Dios P. Carlos Crespi Croci. Santidad, Caridad, Cultura y Progreso, Editorial Abya-Yala, Quito.

- Título de doctor en Ciencias Naturales, conferido el 15 de julio de 1921 all'Università di Padova, Archivo de la Postulación General de las Causas de la Familia Salesiana, Roma. 